Research Article

\title{
Collaborative Innovation Efficiency and Influencing Factors of Civil-Military Integration Enterprises
}

\author{
Zilong Wang, ${ }^{1}$ Zhiwen Zhang $\mathbb{D}^{1},{ }^{1}$ Xiaodi $X u^{2}{ }^{2}$ and Dandan Wang ${ }^{1}$ \\ ${ }^{1}$ College of Economics and Management, Nanjing University of Aeronautics and Astronautics, Nanjing 210016, China \\ ${ }^{2}$ School of Public Administration, Nanjing Normal University, Nanjing 210023, China \\ Correspondence should be addressed to Zhiwen Zhang; zzwnuaa@163.com
}

Received 23 September 2020; Revised 22 December 2020; Accepted 29 December 2020; Published 9 January 2021

Academic Editor: Emilio Jiménez Macías

Copyright (C) 2021 Zilong Wang et al. This is an open access article distributed under the Creative Commons Attribution License, which permits unrestricted use, distribution, and reproduction in any medium, provided the original work is properly cited.

Military-civilian integration has developed into a national strategy. It helps military technology transform into civilian consumer goods but also lets civilian suppliers join the military supply chain. Collaborative innovation is a good method to drive the development of civil-military integration. The measurement of the efficiency of military-civilian integration enterprises' collaborative innovation and analysis of influencing factors are an important basis for making relevant policies. Thus, this paper builds up a two-stage StoNED model. It is used to measure the efficiency of collaborative innovation of civil-military integration enterprises. Then, the Tobit model is used to analyze the influencing factors of innovation efficiency. Here, we show that the overall efficiency and substages efficiency are relatively high, and the low efficiency of the technology R\&D stage is the limiting factor for achieving the optimal overall efficiency. Our results demonstrate that there are differences in the effect of the same factor on efficiency in different substages.

\section{Introduction}

Civil-military integration is a significant issue in national defense and economic development. Against the backdrop of the intensification and upgrading of competition among major countries, making overall plans for development and security is essential to consolidate China's economic and national strength. Collaborative innovation is a good method to drive the development of civil-military integration. Its essence is to promote the effective combination of various production factors required by technological innovation through the rational allocation of resources of all parties. The flow of information, technologies, talents, capital, facilities, services, and other elements between the military and civilian gives emphasis to joint development and the sharing of military and civilian facilities to improve the efficiency of innovation in military technologies and promote the high-quality development of the economy.

Civil-military integration and collaborative innovation are an important part of the national innovation system. For example, the BAE system, Dassault, and Boeing are all typical examples of military-civilian integration. It is the process of achieving military-civilian innovation resource sharing within the national innovation system and by breaking through the barriers among innovation subjects in order to meet the needs of both military and civilian innovation $[1,2]$. That is to say, the military innovation and civil innovation system are integrated, through the sharing of financial resources and technical resources, thus forming synergies. Through this process of integration, the innovation subject absorbs and learns from each other to achieve effective use of resources [3]. Among the military and technological powers in the world, their national economic development has adopted various measures to promote military-civilian technological integration and innovation actively. As a developing country, China's military-civilian technology collaborative innovation more urgently requires the effective allocation of human, financial, and material resources, and limited innovation resources can achieve as much output as possible. Therefore, how to improve the efficiency of collaborative innovation in civil-military integration enterprises and how to avoid inadequate resource investment and redundancy have become urgent problems to be solved. 
The previous research mainly focuses on military-civilian integration management mechanism, collaborative innovation system, and innovation path selection. For example, Haico and Smit [4] thought that it is necessary to attach importance to the cooperation between the civilian and military parties in the development of new technologies. They suggested establishing a "dual-use capability network" to achieve military-civilian technology integration. Brandt [5] pointed out that the biggest problem in the transformation of civil-military integration was to explore new business methods. Guerrero and Urbano [6] analyzed the effect of university-industry-government collaborative innovation on the innovation performance of enterprises in the new economy, especially the impact of collaboration between enterprises and between universities and the government on innovation performance. Dong [2] believed that there was no specialized division of the labor cooperation network system among China's civil-military integration enterprises. The collaborative innovation process was affected by the technological complementarity, interest compatibility, risk controllability, and operational complexity among the innovation entities. Zhao et al. [7] believed that when military-industrial enterprises and civil enterprises shared the cost of technology sharing, the optimal benefits of both parties and the overall benefits of the system would increase. Shao [8] proposed that enterprises should establish a military-civilian interactive communication mechanism and strengthen two-way cooperation.

In the field of innovation efficiency measurement, there are many studies based on DEA and SFA. Zhang et al. [9] applied the SFA method to measure the technical efficiency of listed companies in the national defense science and technology industry and concluded that most enterprises had inefficiencies. Among them, property rights structure was an important factor that affected the technical efficiency of enterprises. Xiao and Lin [10] used the SFA method to measure the efficiency of technological innovation in the industrial sector. They believed that neither direct nor indirect support from the government was conducive to the improvement of technological innovation efficiency. Zhou [11] used the SE-SBM model to measure the economic efficiency of the civil-military integration industry demonstration center. He found that external policies, development environment, and the internal relationship of innovation subjects have obvious positive effects on industrial technology collaborative innovation. In recent years, some studies have considered the staged issues of "technology R\&D" and "technology transformation" in the innovation process. Zhao and Yang [12] used a two-stage DEA model to measure the efficiency of regional innovation networks in the western region from two stages of technological R\&D and economic transformation. The results showed that there were significant regional and stage differences in regional innovation efficiency. Huang [13] used the chain network DEA model to evaluate the university-industry collaborative innovation efficiency. It found that the efficiency of industry-university-research collaborative innovation is low, mainly due to the low efficiency of knowledge transformation. Li et al. [14] distinguished the relationship and difference between "R\&D efficiency," "conversion efficiency," and "innovation efficiency" based on an innovation efficiency evaluation model under the decoupling perspective of "R\&D transformation".
Scholars have also carried out a wealth of research on the factors affecting the implementation of civil-military integration policies and the effectiveness of innovation. Thorgren et al. [15] pointed out that the innovation effect of larger interorganizational collaboration networks was better than that of small interorganizational networks. Also, relevant government policies were conducive to promoting collaborative innovation of enterprises. Burch et al. [16] pointed out two constraints that affect the consistency of civil-military integration policies. One is the expected length of time. The civil sector usually formulated longterm and stable development plans, which lacks sensitivity to unexpected situations. The second was that the complexity of the environment itself would affect the strategic decision-making process. Xie [17] studied the interactive relationship between the factors influencing corporate collaborative innovation and the degree of collaboration. The research results showed that the policy environment factors had the most obvious impact on the degree of collaboration. Yu et al. [18] believed that the market played a decisive role in the depth of collaborative innovation, the intensity of government R\&D investment had nothing to do with the depth of corporate collaborative innovation, and the size of the company was inversely related to the depth of collaborative innovation. Wang and $\mathrm{Li}$ [19] measured the technological efficiency of the civil-military integration enterprises in China's "top ten military industry groups" and concluded that the state-owned shareholding ratio with a high concentration of equity is not conducive to the improvement of enterprise technical efficiency. Dai et al. [20] discussed the current problems in the development of civil-military integration from the perspectives of partner selection, benefit distribution, and exchange mechanisms. The study believed that there was a large gap between China and the developed countries, the depth of civil-military integration is insufficient, the scope of cooperation is not wide, and there was a lack of coordination mechanisms for benefit distribution and risk-taking.

Based on related literature, the current research on the collaborative innovation of civil-military integration has the following limitations: (1) most of the existing literature is a qualitative research study on the civil-military integration management mechanism, innovation system construction, and policy formulation. There is a lack of systematic scientific quantitative research, especially there is not much literature on research from the perspective of efficiency measurement. (2) Most of the discussions on civil-military integration and collaborative innovation are conducted at the macrolevel of regions and industries, and there are still few empirical analyses based on the microlevel of enterprises. (3) In terms of research methods, scholars mostly use the SFA model and the DEA model. The SFA model can effectively separate random errors and nonefficiency terms, but inappropriate production function forms or distribution assumptions of error terms may confuse setting errors and efficiency estimates. There is no need to set the production function form for the DEA model, which avoids the setting error, but it cannot separate the random error [21].

Overall, our article contributes to the existing literature in two important ways. First, breaking through the limitations of the sample, we adopted a microperspective and conducted research based on enterprise-level data. Second, using the two-stage StoNED model to conduct an empirical 
study on the efficiency of collaborative innovation of military-civilian enterprises has reference significance in the method. The research results will help reveal the internal and external influencing factors of military-civilian integrated collaborative innovation and provide a scientific basis for the government to formulate relevant policies.

The remainder of this paper is organized as follows. In Section 2, we introduce the methods and models. Section3 demonstrates the data source and the construction process. Section 4 presents the results of our empirical analysis on the evolution of collaborative innovation efficiency and its influencing factors. Finally, Section 5 concludes.

\section{Methods and Models}

2.1. Dynamic StoNED Model. StoNED (stochastic nonparametric envelopment of data) was proposed by Kwosmanen [22] in 2006, and this method was developed based on the traditional DEA model and SFA model. The model determines the components using the nonparametric processing method of the DEA model and uses the SFA setting method for the introduced random components. The StoNED model first researched the cross-sectional data and believed that the production technology and efficiency items did not change with time. To explain the changes in production technology and efficiency over time, a dynamic StoNED has been developed based on the static models method applied to panel data [22]. Now suppose that the production function can show the changes in production technology and efficiency with time. Incorporate the time variable $t$ into the production function $f$, write the production function as $f(x, t), t=0,1, \ldots, T$, record the random error term as $v_{\mathrm{it}}$, and record the nonefficiency term as $u_{i}(t), i=1,2, \ldots, n$. To reduce the influence of possible heteroscedasticity, the combined residuals adopt the multiplication form instead of the additional form of the original model and then obtain the StoNED model as follows:

$$
y_{\mathrm{it}}=\frac{f\left(x_{\mathrm{it}}, t\right)}{\left(1+u_{i}(t)-V_{\mathrm{it}}\right)},
$$

which is

$$
y_{\mathrm{it}}=f\left(x_{\mathrm{it}}, t\right)-u_{i}(t) y_{\mathrm{it}}+v_{\mathrm{it}} y_{\mathrm{it}} .
$$

If technological progress is an enhanced type of factor input, the production function can be written as

$$
f\left(x_{\mathrm{it}}, t\right)=f\left(x_{\mathrm{it}}, 0\right)+\sum_{m=1}^{M} A_{m}(t) x_{\text {mit }} .
$$

In the above formula, $f\left(x_{\mathrm{it}}, 0\right)$ represents the base production function, and function $A_{m}(t)$ refers to the inputtype technological change. It can be proved that the following properties exist between the base production function and the function $f\left(x_{\mathrm{it}}, t\right)$ : if $f\left(x_{\mathrm{it}}, 0\right)$ is a monotone increasing function and $A_{m}(t) \geq 0, f\left(x_{\mathrm{it}}, t\right)$ is also a monotone increasing function; if $f\left(x_{\mathrm{it}}, 0\right)$ is a concave function, $f\left(x_{i t}, t\right)$ is also a concave function. The above properties show that when setting technological progress under the framework of StoNED, a nonparametric situation can be used to estimate the base production function $f\left(x_{\mathrm{it}}, 0\right)$, and the nonparametric or parametric situations can be used to set the technological progress, and the setting of $A_{m}(t)$ will not affect the concavity of $f\left(x_{i t}, t\right)$.

This article uses quadratic equations to set the technical progress, thereby reducing the introduction of too many unnecessary unknown parameters as follows:

$$
A_{m}(t)=\theta_{m}+\psi_{m} t^{2} .
$$

In the framework of concave nonparametric least squares (CNLS), setting efficiency changes requires imposing many strict constraints to distinguish efficiency changes from random changes. Therefore, we use the parametric equation to estimate the nonefficiency term $u_{i}(t)$, referring to the processing method of Cornwell et al. [23], and setting $u_{i}(t)$ to the form of a quadratic polynomial as follows:

$$
u_{i}(t)=a_{i}+b_{i} t+c_{i} t^{2}
$$

If $b_{i}=c_{i}=0$, the change level of the nonefficiency term is constant; if $b_{i}>0$ and $c_{i}=0$, the nonefficiency term increases linearly. If $c_{i} \neq 0$, it means that the nonefficiency term changes nonlinearly.

To estimate the production function of the base period $f\left(x_{i t}, 0\right)$ and parameters $a, b, c, \alpha, \beta, \theta, \psi$, and $v$, the CNLS estimation model is constructed as follows:

$$
\begin{aligned}
& \min _{a, b, c, \alpha, \beta, \theta, \psi, v} \sum_{t=1}^{T} \sum_{i=1}^{n} v_{\mathrm{it}}^{2} \cdot \\
& \text { s.t. }\left\{\begin{array}{l}
y_{\mathrm{it}}=\alpha_{i t}+\sum_{m=1}^{M} \beta_{\mathrm{mit}} x_{\mathrm{mit}}+\sum_{m=1}^{M}\left(\theta_{m} t+\psi_{m} t^{2}\right) x_{\mathrm{mit}}-\left(a_{i}+b_{i} t+c_{i} t^{2}\right) y_{\mathrm{it}}+v_{\mathrm{it}} y_{\mathrm{it}} \\
\alpha_{\mathrm{it}}+\sum_{m=1}^{M} \beta_{\mathrm{mit}} x_{\mathrm{mit}} \leq \alpha_{h s}+\sum_{m=1}^{M} \beta_{\mathrm{mhs}} x_{\mathrm{mit}} \\
\beta_{\mathrm{mit}} \geq 0 \\
\theta_{m} t+\psi_{m} t^{2} \geq 0 \\
\forall h, i=1, \ldots, n ; \forall s, t=1, \ldots, T \\
\forall m, i=1, \ldots, M
\end{array}\right.
\end{aligned}
$$


Among them, the objective function is to find the minimum value of the sum of squares of random error terms $v_{\mathrm{it}}$. The first constraint represents the production regression equation, and $\alpha_{\mathrm{it}}+\beta_{\mathrm{it}} x_{\mathrm{it}}$ represents its production function $f\left(x_{\mathrm{it}}, 0\right)$. The second constraint is the concave restriction on the tangent hyperplane. The third constraint represents the monotonic production function increasing, and the fourth constraint imposes nonnegative restrictions on technological changes. According to the above constraints, the concave and monotonicity of the production function are guaranteed.

The efficiency $E$ is derived indirectly according to the model (6) and is expressed in the following standardized form as follows:

$$
E_{i}(t)=\frac{1}{1+u_{i}(t)}
$$

2.2. Tobit Model. To further explore the influencing factors of the collaborative innovation efficiency of civil-military integration enterprises, this paper takes the substage innovation efficiency and overall innovation efficiency measured by the two-stage StoNED model as the explained variables and uses each influencing factor as the explanatory variable to set the multiple linear regression equation. Because the efficiency value is limited to a specific interval, which is a truncation problem, this paper uses the Tobit model to analyze the significant influencing factors of the collaborative innovation efficiency of civil-military integration enterprises. The specific model is constructed as follows:

$$
Y_{k}= \begin{cases}X_{k} \beta+\varepsilon_{k}, & X_{k} \beta+\varepsilon_{k}>0, \\ 0, & X_{k} \beta+\varepsilon_{k} \leq 0 .\end{cases}
$$

Among them, $Y_{k}$ is the limited explained variable, which represents the comprehensive efficiency value of the collaborative innovation of the class $k$ civil-military integration enterprise. $X_{k}$ is the explanatory variable, which represents the $k$-th influencing factor of collaborative innovation efficiency, and $\varepsilon_{k}$ is the error term.

\section{Data Source and Variable Selection}

3.1. Data Source. This paper is based on the data of 86 listed companies in the civil-military integration category of China's twelve major military groups. After excluding companies that did not publish R\&D-related data within the research time (2015-2017) and whose listing time was too short (after 2016), a total of 45 listed companies are selected as the research sample. The original data sources of the research mainly come from the China Stock Market and Accounting Research Database, the company's annual report, the China Statistical Yearbook, and China and multinational patent examination information query system of the State Intellectual Property Office. According to the industry attributes of the sample enterprises, they are divided into six categories: nuclear industry enterprises, aerospace industry enterprises, aviation industry enterprises, shipbuilding industry enterprises, weapon industry enterprises, and electronic technology enterprises. The specific classification is shown in Table 1, which shows the number and proportion of various civil-military integration enterprises in the research sample. Among the research samples, the quantity of electronic technology companies is the largest $(28.89 \%)$.

3.2. Variable Selection. Enterprise innovation should be a complex systematic project. The research on innovation efficiency mainly includes two perspectives: one is to analyze innovation activities, and the other is to divide the innovation process into two stages for analysis. The traditional data envelopment model treats the entire system as a "black box", without considering the intermediate process of production activities. It is impossible to analyze the operational efficiency of the intermediate stage of the production process and the impact of each stage on the overall efficiency. The correlation two-stage analytical model can effectively make up for the above deficiencies [24]. Since the two stages of technology $\mathrm{R} \& \mathrm{D}$ and technology transformation are closely linked and both have an impact on innovation efficiency, this paper uses a two-stage research approach to build the input-output indicators for the substages of collaborative innovation efficiency of civil-military integration enterprises (see Table 2).

In the technology $\mathrm{R} \& \mathrm{D}$ stage, the input indicators are mainly considered from the two aspects: human resources and capital [25]. R\&D personnel and R\&D investment are important components of collaborative innovation activities $[26,27]$. Therefore, this paper selects the proportion of $R \& D$ people and the proportion of R\&D investment to operating income as input variables in this stage. Patent is the source of core competitiveness of military-civilian integrated enterprises. The number of patent applications can more comprehensively reflect the scientific and technological output of the enterprise's innovation activities [28], so this variable is selected as the output indicator of the technology R\&D stage [29].

In the technology transformation stage, resource investment is considered from three aspects: human resources, capital, and technology [13]. In terms of human resources, the number of employees at the end of the year is used as the input variable [30]; in terms of capital, the increase in intangible assets is selected as the input variable [31]; in terms of technology, the number of patent applications is used [29]; this variable is the output variable of the technology R\&D stage, which is used as the technology input indicator at this stage. The main output of Stage 2 is the benefits of the application and commercialization of collaborative innovation [32]. Considering the availability of data, we draw on the practices of some scholars and select operating income as the final output indicator [33].

\section{Empirical Analysis}

4.1. Collaborative Innovation Efficiency of Civil-Military Integration Enterprises. This paper takes six major civil-military integration companies of the twelve military-industrial 
TABle 1: Classification of sample enterprises.

\begin{tabular}{lcc}
\hline Type of enterprise & Quantity & Proportion (\%) \\
\hline Nuclear industry enterprises & 2 & 4.44 \\
Aerospace industry enterprises & 10 & 22.22 \\
Aviation industry enterprises & 7 & 15.56 \\
Shipbuilding industry enterprises & 3 & 6.67 \\
Weapon industry enterprises & 10 & 22.22 \\
Electronic technology enterprises & 13 & 28.89 \\
\hline
\end{tabular}

groups as the research object and uses the StoNED model to measure technology R\&D, technology transformation, and overall collaborative innovation efficiency. Based on model (6), the two-stage StoNED model for measuring the efficiency of collaborative innovation in civil-military integration enterprises is expressed in the following form:

$$
\begin{aligned}
& S 1 \min _{a, b, c, \alpha, \beta, \theta, \psi, v} \sum_{t=1}^{3} \sum_{i=1}^{45} v_{\mathrm{it}}^{2}, \\
& \text { s.t. }\left\{\begin{array}{l}
\mathrm{PA}_{i t}=\left[\beta_{\mathrm{Pit}} P_{\mathrm{it}}+\beta_{\mathrm{Qit}} Q_{\mathrm{it}}\right]+\left[\left(\theta_{\mathrm{P}} t+\psi_{P} t^{2}\right) P_{\mathrm{it}}+\left(\theta_{\mathrm{Q}} t\right.\right. \\
-\left(a_{i}+b_{i} t+c_{i} t^{2}\right) \mathrm{PA}_{\mathrm{it}}+v_{\mathrm{it}} \mathrm{PA}_{\mathrm{it}} \\
\beta_{\mathrm{Pit}} P_{\mathrm{it}}+\beta_{\mathrm{Qit}} Q_{\mathrm{it}} \leq \beta_{\mathrm{Phs}} P_{\mathrm{it}}+\beta_{\mathrm{Qhs}} Q_{\mathrm{it}} \\
\beta_{\mathrm{Pit}} \beta_{\mathrm{Qit}} \geq 0 \\
\theta_{P} t+\psi_{P} t^{2} \geq 0 \\
\theta_{\mathrm{Q}} t+\psi_{\mathrm{Q}} t^{2} \geq 0 \\
\forall h, i=1, \ldots, 45 \\
\forall s, t=1,2,3
\end{array}\right. \\
& S 2 \min _{a, b, c, \alpha, \beta, \theta, \psi, v, v} \sum_{t=1}^{3} \sum_{i=1}^{45} v_{\mathrm{it}}^{2}, \\
& \text { s.t. }\left\{\begin{array}{l}
\mathrm{O} R_{\mathrm{it}}=\left[\beta_{\mathrm{Lit}} L_{\mathrm{it}}+\beta_{\mathrm{Kit}} K_{\mathrm{it}}+\beta_{\mathrm{PAit}} P A_{\mathrm{it}}\right]+\left[\left(\theta_{L} t+\psi_{L} t^{2}\right) L_{\mathrm{it}}+\left(\theta_{K} t+\psi_{K} t^{2}\right) K_{\mathrm{it}}\right. \\
\left.+\left(\theta_{\mathrm{PA}} t+\psi_{\mathrm{PA}} t^{2}\right) P A_{\mathrm{it}}\right]-\left(a_{i}+b_{i} t+c_{i} t^{2}\right) O R_{\mathrm{it}}+v_{\mathrm{it}} O R_{\mathrm{it}}, \\
\beta_{\mathrm{Lit}} L_{\mathrm{it}}+\beta_{\mathrm{Kit}} K_{\mathrm{it}}+\beta_{\mathrm{PAit}} P A_{\mathrm{it}} \leq \beta_{\mathrm{Lhs}} L_{\mathrm{it}}+\beta_{\mathrm{Khs}} K_{\mathrm{it}}+\beta_{\mathrm{PAhs}} P A_{\mathrm{it}}, \\
\beta_{\mathrm{Lit}} \beta_{\mathrm{Kit}} \beta_{\mathrm{PAit}} \geq 0, \\
\theta_{L} t+\psi_{L} t^{2} \geq 0, \\
\theta_{K} t+\psi_{K} t^{2} \geq 0, \\
\theta_{\mathrm{PA}} t+\psi_{\mathrm{PA}} t^{2} \geq 0, \\
\forall h, i=1, \ldots, 45, \\
\forall s, t=1,2,3 .
\end{array}\right.
\end{aligned}
$$

The model (9) and model (10) are solved using GAMS software to estimate the relevant parameter values. Finally, the technology R\&D efficiency $E^{S 1}$, technology transformation efficiency $E^{S 2}$, and overall efficiency value of collaborative innovation of civil-military integration enterprises are obtained. The specific data are shown in Table 3.

Table 3 shows the collaborative innovation efficiency value, average value, and coefficient of variation of various types of civil-military integration enterprises from 2015 to 2017. From the overall perspective of the civil-military integration enterprise, the average efficiency of the overall efficiency is 0.8443 , the average efficiency of the technology $\mathrm{R} \& \mathrm{D}$ stage is 0.5014 , and the average efficiency of the technology transformation stage is 0.8204 , indicating that the overall collaborative innovation efficiency and technology transformation efficiency of the civil-military integration enterprise are both high. The level of technology $\mathrm{R} \& \mathrm{D}$ efficiency is in the midstream, and the efficiency of the technology transformation stage is higher than the technology R\&D efficiency.

From the perspective of various types of civil-military integration, the overall efficiency shows industry heterogeneity, the difference is obvious; but the efficiency difference 
TABLE 2: Input-output indicator system.

\begin{tabular}{|c|c|c|c|}
\hline Stage & Index category & Indicator name & Indicator symbol \\
\hline \multirow{3}{*}{ Technology R\&D } & \multirow{2}{*}{ Input variable } & Proportion of R\&D personnel (\%) & $P$ \\
\hline & & Proportion of R\&D investment to operating income ( $\%$ ) & Q \\
\hline & Output variable & Number of patent applications (item) & PA \\
\hline \multirow{4}{*}{ Technology transformation } & \multirow{3}{*}{ Input variable } & Number of employees at year end & $L$ \\
\hline & & Increase in intangible assets & $K$ \\
\hline & & Number of patent applications (item) & PA \\
\hline & Output variable & Operating income (Ten thousand yuan) & OR \\
\hline
\end{tabular}

TABLE 3: Collaborative innovation efficiency value of civil-military integration enterprises.

\begin{tabular}{|c|c|c|c|c|c|c|c|c|c|}
\hline Year & $\begin{array}{c}\text { Efficiency } \\
\text { value }\end{array}$ & $\begin{array}{c}\text { Nuclear } \\
\text { industry } \\
\text { enterprises }\end{array}$ & $\begin{array}{c}\text { Aerospace } \\
\text { industry } \\
\text { enterprises }\end{array}$ & $\begin{array}{c}\text { Aviation } \\
\text { industry } \\
\text { enterprises }\end{array}$ & $\begin{array}{c}\text { Shipbuilding } \\
\text { industry } \\
\text { enterprises }\end{array}$ & $\begin{array}{c}\text { Weapon } \\
\text { industry } \\
\text { enterprises }\end{array}$ & $\begin{array}{l}\text { Electronic } \\
\text { technology } \\
\text { enterprises } \\
\end{array}$ & $\mathrm{CV}$ & Mean \\
\hline \multirow{3}{*}{2015} & $E^{S 1}$ & 0.5007 & 0.5009 & 0.5018 & 0.5000 & 0.5016 & 0.5026 & 0.0018 & 0.5012 \\
\hline & $E^{S 2}$ & 0.7391 & 0.7721 & 0.7912 & 0.8496 & 0.7902 & 0.7887 & 0.0456 & 0.7885 \\
\hline & $E$ & 0.7283 & 0.8683 & 0.7798 & 1.0000 & 0.8089 & 0.8845 & 0.1126 & 0.8450 \\
\hline \multirow{3}{*}{2016} & $E^{S 1}$ & 0.5007 & 0.5008 & 0.5042 & 0.5000 & 0.5018 & 0.5036 & 0.0034 & 0.5018 \\
\hline & $E^{S 2}$ & 0.7369 & 0.8062 & 0.8011 & 0.8850 & 0.8232 & 0.8048 & 0.0586 & 0.8095 \\
\hline & $E$ & 0.7267 & 0.8772 & 0.7788 & 1.0000 & 0.8235 & 0.8639 & 0.1113 & 0.8450 \\
\hline \multirow{3}{*}{2017} & $E^{S 1}$ & 0.5005 & 0.5007 & 0.5014 & 0.5000 & 0.5008 & 0.5034 & 0.0024 & 0.5011 \\
\hline & $E^{S 2}$ & 0.7770 & 0.8728 & 0.8357 & 0.9775 & 0.8566 & 0.8601 & 0.0758 & 0.8633 \\
\hline & $E$ & 0.7358 & 0.8924 & 0.7785 & 0.9251 & 0.8286 & 0.8964 & 0.0886 & 0.8428 \\
\hline \multirow{3}{*}{ Mean } & $E^{S 1}$ & 0.5006 & 0.5008 & 0.5025 & 0.5000 & 0.5014 & 0.5032 & 0.0024 & 0.5014 \\
\hline & $E^{S 2}$ & 0.7510 & 0.8171 & 0.8093 & 0.9040 & 0.8233 & 0.8179 & 0.0596 & 0.8204 \\
\hline & $E$ & 0.7303 & 0.8793 & 0.7790 & 0.9750 & 0.8204 & 0.8816 & 0.1026 & 0.8443 \\
\hline
\end{tabular}

Note. CV (coefficient of variation) represents the coefficient of variation among subsectors.

in the substage is not obvious, especially in the technology R\&D stage, the difference between technology development efficiency of various types of civil-military integration is very small. Among them, electronic technology enterprises have the highest technology R\&D efficiency, which is 0.5032 ; shipbuilding industry enterprises have the highest technology transformation efficiency and overall efficiency of collaborative innovation, respectively 0.9040 and 0.9750 , but the technology R\&D efficiency of such enterprises is the lowest among all sub-industries, which is 0.5000 ; the efficiency of technology transformation and the overall efficiency of collaborative innovation in nuclear industry enterprises are the lowest among all types of civil-military integration enterprises, and their technology R\&D efficiency is also lower than the average level of collaborative innovation technology R\&D efficiency of civil-military integration enterprises. To further analyze the changes in the efficiency of collaborative innovation of civil-military integration enterprises over time and the difference in resource investment, the following gives the trends and changes in the efficiency of overall and substage efficiency of various types of civil-military integration enterprises in collaborative innovation (see Figure 1).

Figure 1 shows the changing characteristics of the efficiency of various civil-military integration enterprises' collaborative innovation in the technology R\&D stage over time. Overall, the trend of the technology R\&D efficiency of the civil-military integration enterprises showed a trend of increasing first and then decreasing. Among them, the

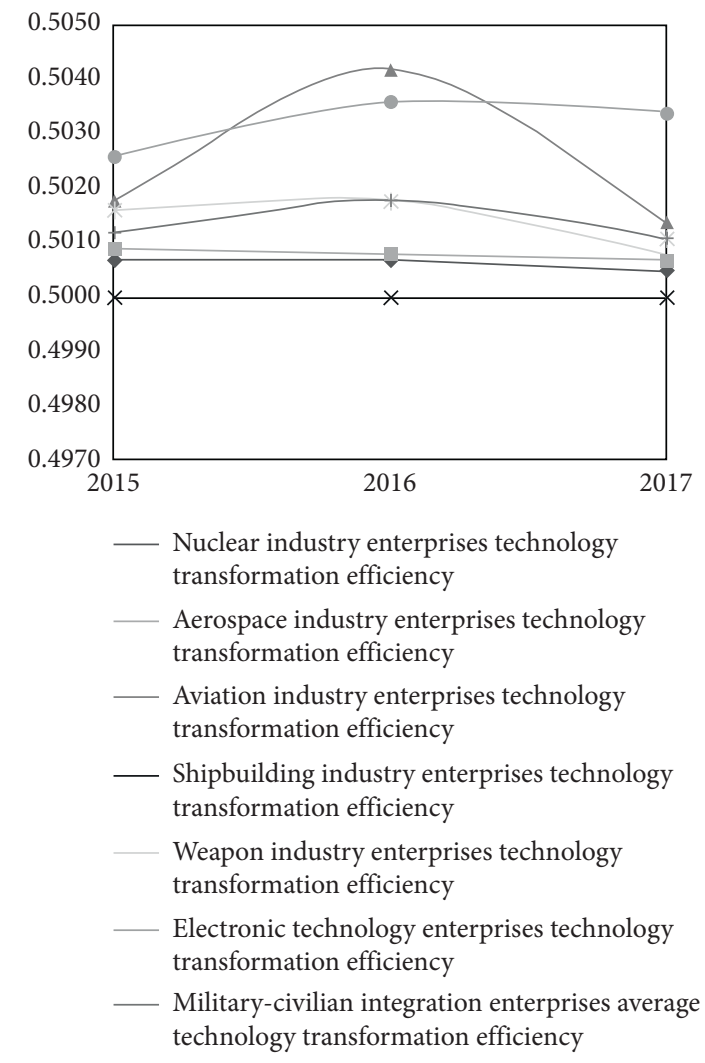

FIGURE 1: Changes in R\&D efficiency of collaborative innovation technology in civil-military integration enterprises. 
efficiency of aviation industry enterprises and electronic technology enterprises in the collaborative innovation technology R\&D stage is higher than the average level of technology R\&D efficiency of civil-military integration enterprises. In 2016, aviation industry enterprises have the highest technology R\&D efficiency. In 2015 and 2017, electronic technology companies have higher technology R\&D efficiency than other types of military-civilian integration companies. The R\&D efficiency of collaborative innovation technology of weapon industry enterprises is close to the average value of technology R\&D efficiency of civil-military integration enterprises. The R\&D efficiencies of collaborative innovation technology of the aerospace industry, nuclear industry, and shipbuilding industry are below average. And the trend of change over time is more stable. The reason may be that these industry-related technologies are at the forefront of science and technology, technology research, and development space is large. However, the difficulty of research and development also increases with the depth of research, so the efficiency of technology research and development is lower than other types of civil-military integration enterprises.

Figure 2 shows the various types of civil-military integration enterprise collaborative innovation in technology transfer stage time-varying characteristics of the passage of efficiency; as a whole, civil-military integration stage companies in the technology transfer efficiency increased year by year, indicating that the resource allocation of collaborative innovation is becoming more and more rational in the process of technology transformation. Among them, the transformation efficiency of the collaborative innovation technology of the shipbuilding industry is significantly higher than that of other types of civil-military integration enterprises. The efficiency value in 2017 is 0.9775 , indicating that the technology application of such enterprises is relatively mature, and new technologies can be quickly put into production and market. The technology transformation efficiencies of aerospace industry enterprises, weapon industry enterprises, electronic technology enterprises, and aviation industry enterprises are close to the average level of technology transformation efficiency of civil-military integration enterprises, and the efficiency value is in the uppermiddle level. The technology transformation efficiency of nuclear industry enterprises is significantly lower than the average level of the technology transformation efficiency of other civil-military integration enterprises. The reason may be that the technology conversion of these enterprises is more difficult, and the transformation period is longer.

Figure 3 shows the trend of the overall efficiency of collaborative innovation of various types of civil-military integration enterprises over time. The overall efficiency of various types of military-civilian integration enterprises has a significant gap, but the overall efficiency of collaborative innovation has not changed significantly over time, and its changes show four different trends. Shipbuilding industry enterprises have the highest overall efficiency of collaborative innovation, with an efficiency value of 1 in 2015 and 2016, indicating that the shipbuilding industry enterprises have a deeper technological accumulation and the

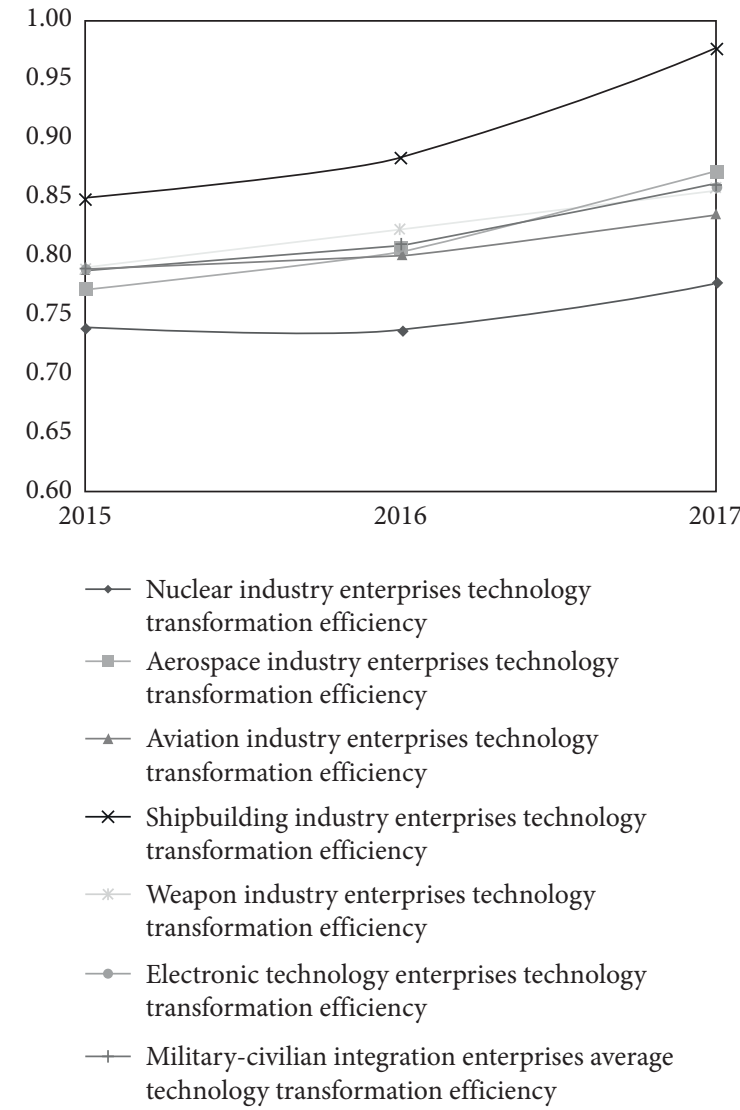

Figure 2: Changes in transformation efficiency of collaborative innovation in civil-military integration.

development of collaborative innovation is superior to other industries, but in 2017 showed a downward trend, possibly because the redundant input of innovation resources began to appear in the collaborative innovation process; the overall efficiency of collaborative innovation of electronic technology companies first decrease and then increase, but the level of efficiency is still relatively high; the overall efficiency of collaborative innovation of aerospace industrial enterprises and weapons industrial enterprises is slowly increasing, indicating that the resource allocation of the two collaborative innovation processes has improved; the overall efficiency of collaborative innovation in nuclear industry enterprises and aviation industry enterprises is lower than the overall efficiency of other types of civil-military integration enterprises, and the efficiency value remains stable over time. Since these two types of civil-military integration enterprises are both types of enterprises that are difficult to tackle. Although the space for technological innovation is large, the technical difficulty also continues to increase with the deepening of exploration.

4.2. Analysis of Influencing Factors. In order to further explore the impact of different factors on the efficiency of collaborative innovation from the enterprise level, this paper uses the Tobit model based on panel data to analyze the influencing factors of collaborative innovation efficiency of 


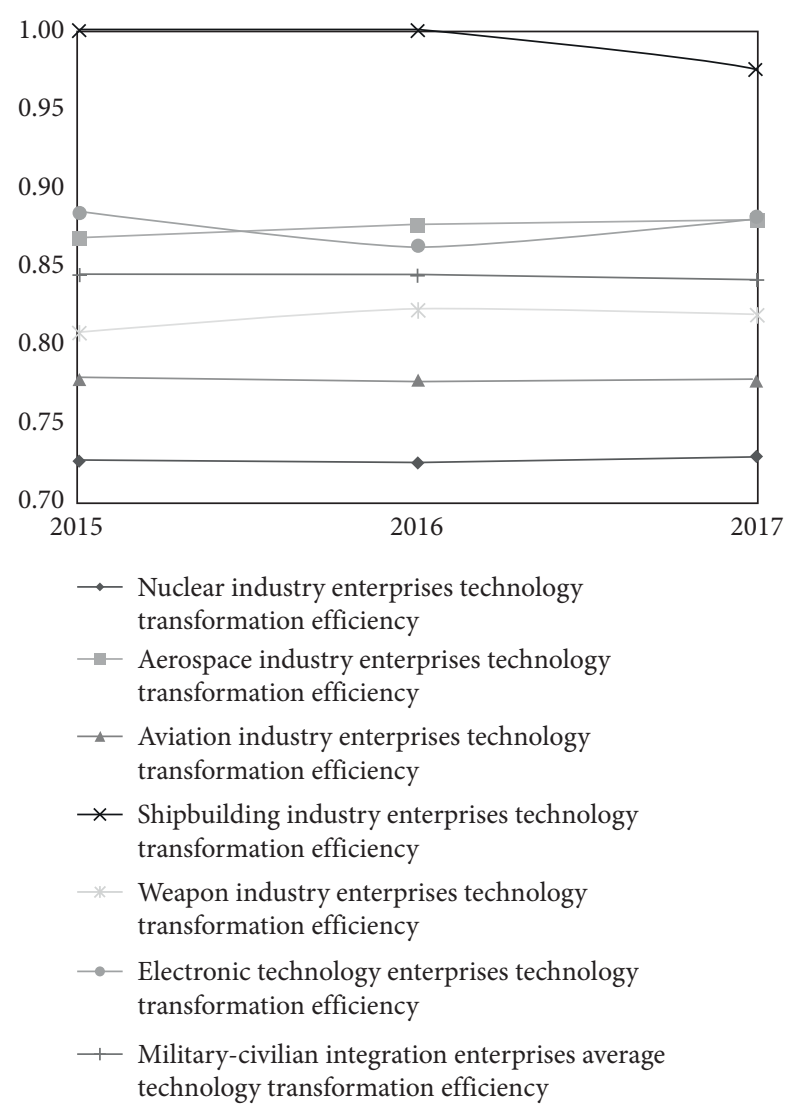

Figure 3: Changes in the overall efficiency of collaborative innovation in civil-military integration enterprises.

civil-military integration enterprises from the following four aspects.

4.2.1. Size of Enterprises (SE). Large enterprises have better resource endowments which are more conducive to the improvement of collaborative innovation efficiency such as sufficient R\&D funds, good R\&D equipment, and perfect management system [34]. Generally speaking, the larger the scale of the enterprise, the more capable the enterprise is to occupy the leading position in R\&D and carry out continuous innovation of knowledge and technology; this article selects the total assets of the enterprise to represent the scale of the enterprise [35].

4.2.2. Ownership Structure (OS). Ownership Structure will affect the fairness and efficiency of enterprises decisionmaking and then affect the operation and stable operation of the enterprise. Over-dispersion of equity increases the risk of R\&D activities and reduces decision-making efficiency, which easily leads to insufficient R\&D investment and lower innovation efficiency. Excessive concentration of equity can easily make major shareholders make "dictatorial" decisions in the production process, which is not conducive to the continuous improvement of production efficiency [36]. This article selects the proportion of the five major shareholders at the end of the period to represent the concentration of enterprise equity.

4.2.3. Market Framework (MF). Monopoly benefits attract leading companies in my country's military-civilian integration industry to improve their own R\&D efficiency [37]. Market framework can reflect the degree of market monopoly or competition in the market, and this paper uses the ratio of the number of companies in the industry to the total number of $a$-share listed companies to measure [38].

4.2.4. Government Favour (GF). Technological innovation activities cannot be separated from government support, and changes in the policy environment, science, and technology innovation policies are the most important leverage tool for the government to promote enterprise scientific and technological innovation [39]. The various policy tools owned by the government can have a significant impact on the choice of collaborative innovation models. For example, the government can influence the effect of collaborative innovation by increasing resource investment in scientific and technological innovation activities [40]. This paper selects the proportion of government subsidy funds in R\&D investment funds to represent the influencing factor.

Based on the model (8), this paper constructs a Tobit model of the factors influencing the efficiency of collaborative innovation of civil-military integration companies and establishes multiple linear regression equations for the civilmilitary integration companies in the overall, technology $\mathrm{R} \& \mathrm{D}$, and technology transformation stages as follows:

$$
\begin{aligned}
& E_{\mathrm{it}}=C+\beta_{1} \ln \mathrm{ES}_{\mathrm{it}}+\beta_{2} \ln \mathrm{OS}_{\mathrm{it}}+\beta_{3} \ln \mathrm{MF}_{\mathrm{it}}+\beta_{4} \ln \mathrm{GF}_{\mathrm{it}}+\varepsilon_{\mathrm{it}}, \\
& E_{\mathrm{it}}^{S 1}=C+\beta_{1} \ln \mathrm{ES}_{\mathrm{it}}+\beta_{2} \ln \mathrm{OS}_{\mathrm{it}}+\beta_{3} \ln \mathrm{MF}_{\mathrm{it}}+\beta_{4} \ln \mathrm{GF}_{\mathrm{it}}+\varepsilon_{\mathrm{it}}, \\
& E_{\mathrm{it}}^{S 2}=C+\beta_{1} \ln \mathrm{ES}_{\mathrm{it}}+\beta_{2} \ln \mathrm{OS}_{\mathrm{it}}+\beta_{3} \ln \mathrm{MF}_{\mathrm{it}}+\beta_{4} \ln \mathrm{GF}_{\mathrm{it}}+\varepsilon_{\mathrm{it}} .
\end{aligned}
$$

In the formula, the explained variables $E_{\mathrm{it}}, E_{\mathrm{it}}^{S 1}$, and $E_{\mathrm{it}}^{S 2}$, respectively, represent the collaborative innovation efficiency of type $i$ enterprises in the year $t$ overall, technology $\mathrm{R} \& \mathrm{D}$, and technology transformation stages. To eliminate the effect of heteroscedasticity, the explanatory variables are all processed logarithmically. $C$ represents the constant term, $\beta_{1}, \beta_{2}, \beta_{3}$, and $\beta_{4}$ is the regression coefficient, and $\varepsilon_{\text {it }}$ represents the random interference term. Using Eviews 8.0 software for regression analysis, the results are shown in Table 4.

From the regression results, the influence of various factors on overall efficiency and substage efficiency is different, and the market structure factors are not significant in the overall and stage efficiency. In the collaborative innovation technology $\mathrm{R} \& \mathrm{D}$ stage of the enterprise, ownership structure factors and market framework factors have not passed the significance test, indicating that these two factors have not played a significant role in the collaborative innovation technology R\&D stage. The regression coefficient of the enterprise-scale factor is -0.00111 , which has passed the $5 \%$ significance test, indicating that the enterprise scale is 
TABLE 4: Tobit regression results of factors affecting the efficiency of collaborative innovation in civil-military integration enterprises.

\begin{tabular}{|c|c|c|c|c|c|c|c|c|c|}
\hline & \multicolumn{3}{|c|}{ S1 } & \multicolumn{3}{|c|}{ S2 } & \multicolumn{3}{|c|}{ Overall } \\
\hline & Coefficient & Standard deviation & $P$ value & Coefficient & Standard deviation & $P$ value & Coefficient & Standard deviation & $P$ value \\
\hline$\beta_{1}$ & $-0.00111^{* *}$ & 0.00044 & 0.0118 & $0.03893^{* * *}$ & 0.00668 & 0.0001 & $0.03711^{* * *}$ & 0.00676 & 0.0001 \\
\hline$\beta_{2}$ & 0.00094 & 0.00130 & 0.4684 & $-0.06194^{* * *}$ & 0.01978 & 0.0017 & $-0.07738^{* * *}$ & 0.02001 & 0.0001 \\
\hline$\beta_{3}$ & -0.00009 & 0.00052 & 0.8643 & 0.00910 & 0.00786 & 0.2471 & -0.00450 & 0.00795 & 0.5714 \\
\hline$\beta_{4}$ & $0.00063^{* *}$ & 0.00029 & 0.0313 & -0.00348 & 0.00447 & 0.4360 & -0.00482 & 0.00452 & 0.2864 \\
\hline$C$ & $0.51253^{* * *}$ & 0.00850 & 0.0001 & 0.22522 & 0.12923 & 0.0814 & $0.35703^{* * *}$ & 0.13072 & 0.0063 \\
\hline
\end{tabular}

${ }^{* * *}$ The significance level at $1 \%,{ }^{* *}$ the significance level at $5 \%$, and ${ }^{*}$ the significance level at $10 \%$.

inversely related to the R\&D efficiency of collaborative innovation technology of civil-military integration enterprises. That is, the larger the enterprise size, the lower the R\&D efficiency of collaborative innovation technology. Maybe due to the time lag, the high investment in the technology R\&D stage could not be converted to the corresponding output in a short period, resulting in low efficiency of technology R\&D [41]. The regression coefficient of government favor factors is 0.00063 , which has passed the $5 \%$ significance test, indicating that policy support is positively correlated with the efficiency of collaborative innovation technology R\&D in civil-military integration enterprises.

In the stage of enterprise collaborative innovation technology transformation, market framework factors and government support factors have not passed the significance test, indicating that these two factors have not played a significant role in the stage of collaborative innovation technology transformation. The regression coefficient of the enterprise-scale factor is 0.03893 , which passes the significance level at $1 \%$, indicating that the enterprise scale is positively related to the transformation efficiency of the collaborative innovation technology of civil-military integration enterprises. The larger the scale of the enterprise, the higher the efficiency of technology transformation. The reason may be that the larger the scale of the enterprise, the easier it is for innovative technologies to be applied to products and marketed. The regression coefficient of the ownership structure factor is -0.06194 , which passes the significance level at $1 \%$, indicating that the ownership structure is negatively related to the transformation efficiency of collaborative innovation technology of civilmilitary integration enterprises. The more concentrated the ownership, the lower the efficiency of collaborative innovation technology transformation. Too concentrated equity will lead to a lack of democracy in decision-making, which will inhibit the efficiency of collaborative innovation technology transformation.

As far as the overall efficiency of civil-military integration collaborative innovation is concerned, market framework factors and government favor factors have no significant effect on the efficiency of collaborative innovation. The regression coefficient of the enterprise-scale factor is 0.03711 , which passes the significance level at $1 \%$, indicating that the enterprise-scale factor is positively related to the overall efficiency of civil-military integration collaborative innovation. The larger the enterprise scale, the higher the overall efficiency of collaborative innovation. The regression coefficient of the ownership structure factor is -0.07738 , which passes the significance level at $1 \%$, indicating that the ownership structure is negatively related to the overall efficiency of civilmilitary integration innovation. That is, the more concentrated the ownership, the lower the efficiency.

\section{Conclusions}

The calculation and analysis of the factors influencing the efficiency of collaborative innovation in civil-military integration enterprises are the basis and premise for further improving the level of collaborative innovation in civilmilitary integration. This paper uses a two-stage StoNED model to measure the overall efficiency and stage efficiency of 45 Chinese listed civil-military integration listed companies from 2015 to 2017 and uses the Tobit model to perform regression analysis on the factors that affect efficiency. The main conclusions were as follows:

(1) The overall collaborative innovation efficiency of civil-military integration enterprises is at the uppermiddle level, indicating that there is still more room for improvement in resource allocation, and efforts must be made to solve problems such as resource redundancy or waste. The efficiency of the collaborative innovation technology $\mathrm{R} \& \mathrm{D}$ stage is low, and the efficiency of the technology transformation stage is at a high level. The efficiency difference of various civil-military integration companies in the technology R\&D stage is small, and the efficiency difference is obvious in the technology transformation stage. During the sample period, the overall efficiency of collaborative innovation has changed smoothly, with a slight improvement. Technology R\&D efficiency shows a trend of increasing first and then decreasing. The transformation stage showed a clear upward trend.

(2) The scale of the enterprise has a negative effect on the efficiency of the civil-military integration innovation technology R\&D stage and has a positive effect on the technology transformation efficiency and the overall efficiency. The expansion of the enterprise scale leads to a reduction in intermediate output efficiency and promotes the improvement of final output efficiency; ownership concentration degree has a negative effect on the overall innovation and technology transformation efficiency of civil-military integration enterprises. The more concentrated the ownership, the lower the efficiency. 
(3) Most of the sample enterprises of civil-military integration within the study period are large-scale military enterprises. Due to its characteristics, the market framework has no significant effect on collaborative innovation. Government favor mainly has a positive impact on the efficiency of collaborative innovation technology $\mathrm{R} \& \mathrm{D}$, indicating that government favor in terms of funds and policies is conducive for promoting collaborative innovation technology $\mathrm{R} \& \mathrm{D}$ in civil-military integration enterprises.

In response to the research conclusions, this paper puts forward corresponding policy recommendations to improve the efficiency of civil-military integration collaborative innovation as follows:

(1) At present, there are still certain defects in the deployment of civil-military integration collaborative innovation resources. The technology $\mathrm{R} \& \mathrm{D}$ stage is the limiting factor for the failure to achieve the optimal efficiency of civil-military integration collaborative innovation. It is necessary to focus on improving the scientific allocation of innovation resources at this stage, strengthening the technological R\&D capabilities of enterprises, and promoting the full use of innovation resources.

(2) Civil-military integration enterprises should rationally optimize the scale structure of enterprises, attach importance to the innovation power of small- and medium-sized enterprises, and can expand the scale of enterprises through mergers and acquisitions, reorganization, and other restructuring methods and absorb small- and medium-sized enterprises with strong innovation and R\&D capabilities to enter the defense field and promote the rational allocation of innovation resources; enterprises should also rationally diversify their ownership and avoid the concentration of ownership. They can take the form of shareholding incentives to promote technological innovation.

(3) The government should actively formulate relevant preferential policies for collaborative innovation of civil-military integration enterprises, including taxation, preferential benefits, and priority in resource allocation and ensure that scientific and technological R\&D funds are effectively invested in the field of corporate collaborative innovation. The government can encourage "military to civilian" and promote military-industrial enterprises to expand the civilian market, encourage "civilians to military," undertake some military R\&D tasks, and avoid wasting resources between the military and the local.

\section{Data Availability}

The R\&D-related data used to support the findings of this study may be released upon application to the China Stock
Market\&Accounting Research Database (https://www. gtarsc.com/).

\section{Conflicts of Interest}

The authors declare that there are no conflicts of interest regarding the publication of this paper.

\section{Acknowledgments}

This work was supported by the Chinese National Funding of Social Sciences (Grant no. 18AGL028).

\section{References}

[1] D. Korski, "British civil-military integration," The RUSI Journal, vol. 154, no. 6, pp. 14-24, 2009.

[2] X. H. Dong, "The review and theoretical framework on the collaborative innovation of military-civil integration industrial cluster," Chinese Journal of Systems Science, vol. 21, no. 4, pp. 60-64, 2013.

[3] J. C. Y. Ng and M. D. Huang, "Policy harmonization mechanisms concerning civil-military integration and green development," Journal of Nanjing University of Science and Technology, vol. 32, no. 1, pp. 6-23, 2019.

[4] T. K. Haico and W. A. Smit, "Civilian-military co-operation strategies in developing new technologies," Research Policy, vol. 32, no. 6, pp. 955-970, 2003.

[5] L. Brandt, "Defense conversion and dual-use technology. The push toward civil-military integration," Policy Studies Journal, vol. 22, no. 2, pp. 359-370, 1994.

[6] M. Guerrero and D. Urbano, "The impact of triple helix agents on entrepreneurial innovations' performance: an inside look at enterprises located in an emerging economy," Technological Forecasting and Social Change, vol. 119, no. 1, pp. 294-309, 2017.

[7] L. M. Zhao, J. H. Sun, and H. B. Zhang, "Technology sharing behavior in civil-military integration collaborative innovation system based on differential game," Journal of Industrial Engineering and Engineering Management, vol. 31, no. 3, pp. 183-191, 2017.

[8] Y. Shao, "Research on obstacle factors and countermeasures of collaborative innovation of military and civilian integration," Scientific Management Research, vol. 224, no. 3, pp. 11-14, 2018.

[9] X. Zhang, N. C. Hou, and C. J. Li, "The technical efficiency of national defense science and technology industrial enterprises under the micro-view of military-civilian integration," Reform of Economic System, vol. 1, no. 3, pp. 96-100, 2013.

[10] W. Xiao and G. B. Lin, "Government support, research and development management and technological innovation efficiency," Management World, vol. 247, no. 4, pp. 71-80, 2014.

[11] B. Zhou, "Analysis and promotion of factors influencing the technological synergy of military-civilian fusion industry," Science \& Technology Progress and Policy, vol. 32, no. 11, pp. 87-92, 2015.

[12] W. P. Zhao and H. Z. Yang, "Evaluation of western innovation network efficiency based on DEA," Science Research Management, vol. 1, no. 37, pp. 393-400, 2016.

[13] J. J. Huang, "Research on the university-industry collaborative innovation efficiency and its affecting factors," Soft Science, vol. 31, no. 5, pp. 38-42, 2017.

[14] M. N. Li, F. Huang, W. S. Wang, and Y. Q. Zhu, "Assessing the innovation efficiency based on the decoupling perspective of 
"R\&D-commercialization," Science of Science and Management of S.\& T.vol. 1, no. 9, pp. 52-69, 2017.

[15] S. Thorgren, J. Wincent, and D. Örtqvist, "Designing interorganizational networks for innovation: an empirical examination of network configuration, formation and governance," Journal of Engineering and Technology Management, vol. 26, no. 3, pp. 148-166, 2009.

[16] A. Burch, B. R. Higgins, C. A. Jennings et al., Towards a Comprehensive Approach: Integrating Civilian and Military Concepts of Strategy, Research Division, NATO Defense College, Rome, Italy, 2011.

[17] X. M. Xie, "An empirical study on multidimensional relationships between factors of synergic innovation of firms and their synergic degree," Science Research Management, vol. 36, no. 2, pp. 69-78, 2015.

[18] L. P. Yu, S. W. Li, and J. Liu, "Influence mechanism of enterprise synergy innovation depth in the case of high technology industry," Forum on Science \& Technology in China, vol. 1, no. 12, pp. 54-59, 2016.

[19] B. J. Wang and A. W. Li, "An analysis on calculation and influencing factors of the technical efficiency in civil-military integration enterprises," Science and Technology Management Research, vol. 36, no. 23, pp. 67-73, 2016.

[20] Y. Dai, G. Sun, and H. Song, "Research on the present situation and countermeasures of the collaborative innovation of civil-military integration," Journal of Chongqing University of Technology, vol. 31, no. 6, pp. 64-70, 2017.

[21] Y. L. Ji and L. Q. Zhao, "A new method of efficiency measurement: random nonparametric data envelopment analysis," Statistics and Decision, vol. 1, no. 5, pp. 35-36, 2011.

[22] T. Kuosmanen, Stochastic Nonparametric Envelopment of Data: Combining Virtues of SFA and DEA in a Unified Framework, MTT Agrifood Research Finland, Jokioinen, Finland, 2006.

[23] C. Cornwell, P. Schmidt, and R. C. Sickles, "Production frontiers with cross-sectional and time-series variation in efficiency levels," Journal of Econometrics, vol. 16, no. 2, pp. 185-200, 1990.

[24] C. Kao, "Efficiency decomposition in network data envelopment analysis: a relational model," European Journal of Operational Research, vol. 192, no. 3, pp. 949-962, 2009.

[25] M. Buesa, J. Heijs, and T. Baumert, "The determinants of regional innovation in Europe: a combined factorial and regression knowledge production function approach," $R e$ search Policy, vol. 39, no. 6, pp. 722-735, 2010.

[26] H. Graf and T. Henning, Public Research in Regional Networks of Innovators: A Comparative Study of Four East-German Regions: Entrepreneurship and Culture, Springer, Berlin, Heidelberg, 2010.

[27] R. Cowan and N. Zinovyeva, "University effects on regional innovation," Research Policy, vol. 42, no. 3, pp. 788-800, 2013.

[28] D. Czarnitzki and K. Hussinger, "The link between R\&D subsidies, R\&D spending and technological performance," ZEW-Centre for European Economic Research Discussion, vol. 456 pages, 2004.

[29] X. Li, "China's regional innovation capacity in transition: an empirical approach," Research Policy, vol. 38, no. 2, pp. 338-357, 2009.

[30] Y. Z. Yu, "The efficiency of technological innovation in China's high-tech industry and its influence factors," Economic Science, vol. 1, no. 4, pp. 62-74, 2009.

[31] Y. J. Zhang and L. Li, "Innovation-driven strategy make grinders military private enterprises of science and technology resources allocation," Science \& Technology Progress and Policy, vol. 33, no. 23, pp. 116-122, 2016.

[32] Z. Q. Yang, "The study on technology innovation efficiency and its influence factors of our country's GEM listed," Forward Position or Economics, vol. 3, no. 3, pp. 151-160, 2012.

[33] Z. Wang, Z. Zhang, and N. C. Y. Jhony, "Measurement of innovation resource allocation efficiency in civil-military integration enterprises," Kybernetes, vol. 49, no. 3, pp. 835-851, 2019.

[34] L. Hans and H. Almas, "On the relationship between innovation and performance: a sensitivity analysis," Economics of Innovation and New Technology, vol. 15, no. 4-5, pp. 317-344, 2006.

[35] C. T. Chen, C. F. Chien, M. H. Lin, and J. T. Wang, "Using DEA to evaluate R\&D performance of the computers and peripherals firms in taiwan," International Journal of Busines, vol. 4, no. 2, pp. 348-360, 2006.

[36] M. Feng and D. D. Sun, "Study on the influence of listing corporation factors of earnings quality GEM," Soft Science, vol. 28, no. 8, pp. 137-140, 2014.

[37] Y. Z. Yu, P. Wu, and J. B. Lin, "Research on the efficiency of research and development in China's high-tech industry segments from the perspective of value chain," Science of Science and Management of S.\& T.vol. 31, no. 5, pp. 60-65, 2010.

[38] J. L. Chen, L. J. Meng, and C. L. Jiang, "The research on technological innovation efficiency and its affecting factors of high-tech industry from two-stage perspective," Mathematics in Practice and Theory, vol. 44, no. 4, pp. 63-74, 2014.

[39] H. T. Zhou and Y. H. Lin, "Research on the construction of market-oriented policy of government support for scientific and technological innovation of enterprises: base on the theoretical for scientific and technological innovation of enterprises," Science of Science and Management of S.\& T.vol. 37, no. 5, pp. 3-16, 2016.

[40] W. Dolfsma and D. Seo, "Government policy and technological innovation-a suggested typology," Technovation, vol. 33, no. 6-7, pp. 173-179, 2013.

[41] D. C. Fan and M. Y. Du, "Research on technological innovation resource allocation efficiency and its influencing factors in high-end equipment manufacturing industries," Chinese Journal of Management Science, vol. 26, no. 1, pp. 13-24, 2018. 